\title{
La vida buena de Sebastião Salgado: una lectura de La Sal de la Tierra
}

\author{
La sal de la tierra | Wim Wenders y Juliano R. Salgado | 2014
}

Juan Manuel González*

Universidad de Monterrey

Recibido 26 de marzo de 2020; aprobado 15 de abril de 2020

\begin{abstract}
Resumen
Partiendo de la propuesta de Sinnerbrink para la aproximación ética a las obras cinematográficas y enmarcado en la aspiración ética de Ricoeur de tender a una vida buena, se analiza la película documental La sal de la tierra de los directores Wim Wenders y Juliano R. Salgado. El texto estudia los problemas éticos que presupone la representación del dolor y sufrimiento de los otros en torno a la narrativa de una vida bien vivida en referencia al fotógrafo brasileño Sebastião Salgado, en los niveles del texto, los autores, la recepción crítica y perspectivas histórico-culturales e ideológicas.
\end{abstract}

Palabras Clave: Wenders | Salgado | ética | representación

The good life of Sebastião Salgado: analysis of the film The Salt of the Earth

\begin{abstract}
Based on Sinnerbrink's proposal for the ethical approach to cinematographic works and framed by Ricoeur's ethical aspiration of tending to a good life, the article analyzes the documentary film The Salt of the Earth by directors Wim Wenders and Juliano R. Salgado. The text studies the ethical problems that arise from the representation of the pain and suffering of others around the narrative of a life well lived, in reference to the Brazilian photographer Sebastião Salgado, at the levels of the text, the authors, critical reception and historical, cultural and ideological perspectives.
\end{abstract}

Keywords: Wenders | Salgado | ethics | representation

\section{A manera de introducción}

Hay muchas formas y razones de acercarse a la interpretación de los textos cinematográficos. El discurso audiovisual es rico en capas de contenido que unen prácticamente todos los mecanismos significantes visuales y sonoros en entretejidos de alta complejidad. Estos textos audiovisuales ofrecen a los espectadores experiencias narrativas que consumen ávidamente y que decodifican en distintos niveles de entendimiento.

En el presente artículo el interés es acercarse a presentar posibles avenidas de interpretación ética del texto cinematográfico La sal de la tierra (The Salt of the Earth, Wenders, Salgado y Rosier, 2014), documental de largometraje dirigido por el cineasta alemán Wim Wenders y el realizador brasileño Juliano Ribeiro Salgado. El documental narra en poco menos de dos horas la vida y carre- ra del fotógrafo brasileño afincado en Francia, Sebastião Salgado (padre del co-director), relatando su exilio de Brasil en los años 60, su descubrimiento de la fotografía, su éxito como relator de las grandes empresas, crisis humanitarias y guerras del hombre, su desencanto de la humanidad, y su retorno a Brasil para descubrir una nueva esperanza a través del reencuentro con la tierra que heredó de sus padres y abuelos. En este relato, se cuenta la historia del fotógrafo desde sus épocas juveniles en la escuela hasta su séptima década, presentando un amplio panorama de la existencia de un hombre. La vida de Sebastião Salgado es narrada en la cinta primordialmente a partir de su obra fotográfica, presentada cronológicamente en el documental, y que recorre más de cuarenta años. Wenders y J. Salgado utilizan este recorrido para narrar el viaje profesional y moral del fotógrafo en su película. La sal de la tierra se estrenó en el Festival de

* juan.gonzalezf@udem.edu 
Cannes, donde obtuvo tres premios, y tuvo una importante carrera de festivales para eventualmente tener su estreno comercial y obtener una nominación al Oscar en 2015 (imdb.com, s.f.).

Paul Ricoeur, en sus tres volúmenes de Tiempo y narración $(2004,2009)$ y posteriormente en Sí mismo como otro (2006), aborda la construcción de la identidad narrativa, y como dice Manuel Maceiras (2004), propone entender la vida de un ser humano como un relato. Un relato donde mantiene la convicción "de que el yo del conocimiento de sí es el resultado de una vida examinada, contada y retomada por la reflexión aplicada a las obras, a los textos, a la cultura" (Maceiras, 2004, p.28). Es a partir de esta vida contada que Ricoeur plantea su postura ética, la que declara como su aspiración: “Tender a la vida buena..." (Ricoeur, 2006, p. 176) “...con y para el otro...” (Ricoeur, 2006, p. 186), “...en instituciones justas" (Ricoeur, 2006, p. 202). Esta intencionalidad ética, la de "la aspiración de una vida cumplida bajo el signo de las acciones estimadas buenas" (Ricoeur, 2002, p. 241), unida a sus propuestas narrativas, permite a Karl Simms asegurar que Ricoeur define la meta del ser humano como "hacer la historia de nuestra vida una buena historia” (Simms, 2003, loc. 133, trad. propia). Así, la narrativa personal se convierte en un elemento esencial de los argumentos de Ricoeur, tomando prestado de Alasdair MacIntyre el concepto de "unidad narrativa de una vida" (Ricoeur, 2006, p. 159) para referirse a la suma de prácticas y proyectos que integran el relato de una existencia humana.

Esta narrativa de vida que presenta $L a$ sal de la tierra permite acercarse a la interpretación ética de la película a través de la metodología de análisis que describe Sinnerbrink (2016) y que se propone para este estudio. Mediante la exploración de los tres niveles que propone el autor, se realizará una lectura de ciertos aspectos del filme en su primera denotación, en la intencionalidad de los autores y la ideología profunda, nivel que Ricoeur identifica como ideal para el análisis del discurso.

\section{Cine y ética}

Badiou (2004), en su texto El cine como experimentación filosófica, nos dice que a lo largo de la historia del cine han existido cinco intentos de "entrar al problema" de estudiar el cine desde la filosofía y uno de ellos es su significancia ética. Es precisamente esta significancia la que lleva a Sinnerbrink (2016) partiendo de Badiou, a preguntarse cómo ha sido el enfoque ético en el estudio del cine y concluir que si bien la mayoría de los acercamientos filosóficos al cine han sido ontológicos, epistemológicos, estéticos o fenomenológicos, la ética ha estado presente sin ser "temática". Sinnerbrink argumenta que "la ética en el cine (y el cine como ética) representa mucho más que una rama menor de la filosofía del cine" y que "se puede argumentar que es la manera más culturalmente significativa en la que el cine se puede entender filosóficamente" ya que nos permite mejorar nuestra habilidad de "relacionarnos con formas complejas de la experiencia moral" (Sinnerbrink, 2016, loc. 376, todas las citas del artículo cuyo idioma original no es el español son traducción del autor).

Sinnerbrink (2016, loc. 403) propone tres acercamientos al estudio ético del cine con base en su relación película-productor/espectador-contexto: 1, "La ética en el cine", es decir el estudio de las situaciones narrativas y dramáticas que invocan la presencia de la ética para resolverse; 2, "Las éticas (o políticas) de la representación cinematográfica” tanto en su producción como en su recepción; y 3, la "ética del cine como un medio cultural que expresa creencias morales, valores sociales o ideología”. El autor, propone que la relación entre estos acercamientos es importante, pero declara que el mayor reto es el de "pensarlos juntos", ya que "los tres aspectos contribuyen a nuestro entendimiento de las dimensiones ético-políticas del cine".

La metodología que propone Sinnerbrink (2016) para el estudio de la ética en el cine puede, en esencia, aplicarse al estudio de cualquier obra cinematográfica. Sin embargo, el caso particular de La sal de la tierra trata del acercamiento a una obra de largometraje documental, que incluye secuencias narrativas, entrevistas, imágenes fijas, intervención de los realizadores, y muchas otras técnicas propias del género. En este sentido, será necesario también orientar el estudio alrededor del pensamiento ético sobre la realización documental, donde prevalece "la premisa y asunción de que lo que ocurre frente a la cámara no se representó en su totalidad pensando en la cámara” como lo dice Bill Nichols (1997, p. 177).

Nivel 1. La ética en La sal de la tierra

Sinnerbrink (2016, loc. 411) habla de que en el primer nivel de acercamiento al estudio de la ética cinematográfica, muchos estudiosos se han "enfocado en la ética dentro de la representación cinematográfica (temas moralmente relevantes, problemas y argumentos dentro de la 
narrativa o acercamientos al cine como un 'experimento del pensamiento')".

Siendo un documental, La sal de la tierra presenta hechos que son inmutables y parte de la historia de los personajes, en la que están inmersos los documentalistas. Así, las imágenes presentadas son el primer soporte de análisis. Es el nivel de la denotación primaria.

En la película, las fotografías realizadas por Salgado a lo largo de su carrera son las que toman el lugar protagónico. Esta presentación de las imágenes a cuadro (que incluso utiliza un formato de diferentes proporciones a las secciones filmadas originalmente para la película) ingesta el significado de la obra del fotógrafo (S. Salgado) a la de los directores.

Así, de la misma manera que La sal de la tierra (2014) presenta paisajes que dejan al espectador sin respiro, la película muestra las imágenes que Salgado creó en sus viajes por diversos continentes retratando a los más vulnerables en las situaciones más difíciles. Esta carga significante la absorbe también el documental y es la operación de su lectura la que genera mayor impacto en los públicos.

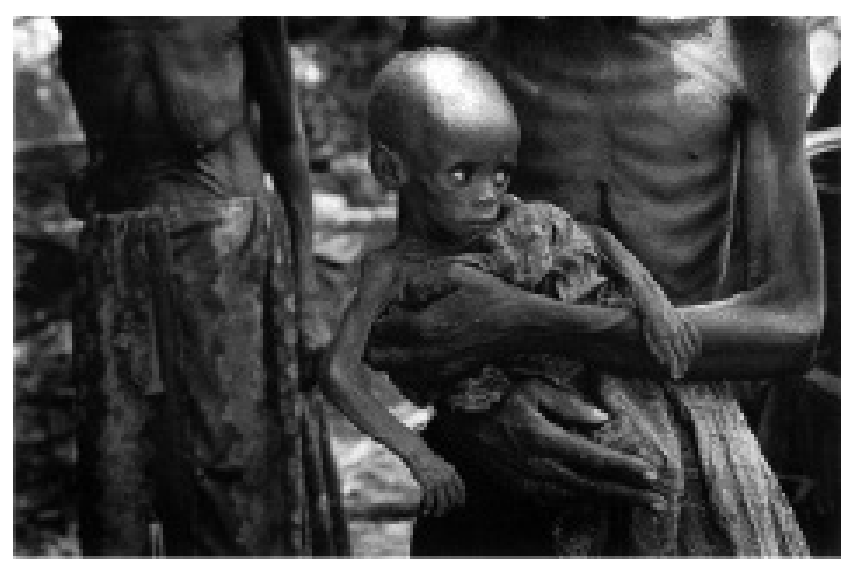

Al tener tal primacía, las imágenes ciertamente bellas pero desgarradoras, mueven al escándalo y el sentimentalismo. Sus retratos de las hambrunas en África, de vivos y muertos, son igualmente terribles. Imágenes que ofrecen montones de cadáveres, evidencias del genocidio y desolación e invitan a retirar pudorosamente la vista. Sebastião Salgado, desde su primer proyecto, centra su obra fotográfica en la representación de los menos afortunados. Aquellos con los que tiene una diferencia no solo social y económica, sino formas distintas de entender al mundo que pueden situar a los sujetos en posiciones de vulnerabilidad ante la cámara. Salgado no se detiene al capturar con su cámara el dolor y la muerte de sujetos anónimos. Los directores de La sal de la tie- rra adoptan la mirada de Sebastião Salgado a través del uso de sus imágenes.

Salgado a lo largo del filme describe las circunstancias en las que realizó las fotografías y cuenta un poco de los personajes que en ellas aparecen o el contexto en que fueron tomadas. En múltiples ocasiones el fotógrafo habla de su perspectiva respecto a lo que retrata, muchas veces siendo auto-apologético, especialmente tras la cobertura del genocidio en Ruanda y la guerra en Yugoslavia. Larry Rother en el New York Times, lo cita diciendo:

"Estaba completamente exhausto, consumido por lo que había visto allí", él dijo. "Sentí el impacto de las cosas absolutamente terribles que nuestra especie ha hecho y terminé enfermándome. Verdaderamente enfermo, mentalmente, y eso se reflejaba en mi salud, mi cuerpo". (Rother, 2015)

Susan Sontag en Regarding the pain of others (2003) critica profundamente el enfoque de Salgado, calificando su retórica de mojigata y resaltando el "trato ácido" que han recibido las imágenes por su exhibición y comercialización de la miseria. Sin embargo, su crítica más dura la hace sobre el contenido mismo de las fotografías, que podríamos extender a su presentación en el documental: "su enfoque en los desempoderados, reducidos a su desempoderamiento" de manera anónima y sin representar sus “ocupaciones, etnicidades, y apuros” (Sontag, 2003, loc. 721-728). En el mismo tono, A.O. Scott para cerrar su crítica de La sal de la tierra en The New York Times comenta que, a pesar del talento y la decencia de Salgado, “sus imágenes, precisamente porque revelan verdades ásperas y no bienvenidas, merecen una mirada crítica más dura y robusta” (Scott, 2014).

El sitio Rotten Tomatoes (www.rottentomatoes. com), que concentra las opiniones de críticos y audiencias, presenta la siguiente como sinopsis de la cinta, recalcando su fragilidad ética:

Si bien la obra que honra puede plantear cuestiones éticas espinosas que La sal de la tierra se niega a responder, sigue siendo un testimonio demoledor y estimulante de la carrera de Sebastião Salgado. (www.rottentomatoes.com, s.f.)

A pesar de que se puede intentar hacer una separación entre las imágenes del fotógrafo y la narración que se hace de su vida, el espectador en su primera lectura no hace esta diferencia. La interpretación ética de estas fotografías levanta evidentes cuestionamientos sobre la captura, embellecimiento y comercialización de las imágenes del sufrimiento de los demás. 


\section{Nivel 2. Las éticas (o políticas) de la representación cinematográfica en La sal de la tierra}

El segundo acercamiento de Sinnerbrink a la ética cinematográfica es la exploración de la "ética de la representación cinematográfica, desde la perspectiva del cineasta (producción) o del espectador (recepción)" (2016, loc. 422). Se hará primeramente un acercamiento a las declaraciones que los cineastas han hecho en entrevistas sobre la película y posteriormente se estudiará la recepción que ha tenido la cinta, representada por la voz de la crítica.

La primera intención de los directores es precisamente narrar la vida de Salgado, quizá con propósitos distintos. Wenders dice, en entrevista con Stephen Saito (2015, marzo 27), que considera que una de las últimas aventuras del planeta es el proceso creativo, y por eso al acercarse a Salgado relata, "Mi pregunta inicial era realmente qué es lo que impulsa a Sebastião. ¿Qué impulsa a este hombre a completar esta obra increíble?”. Mientras que para Ribeiro Salgado la principal razón era la necesidad de preservar las memorias de su padre, como lo narra en la entrevista que otorgó al Festival de Cine de Morelia: "Todo lo que Sebastián contaba de sus viajes cada vez que volvía, y todo lo que me transmitía a mí, pero también a la familia, a los amigos, que era una experiencia del mundo increíble... una humanidad en situaciones muchas veces de desesperación, y unas cosas que Sebastián había aprendido de ellos, que eran muy bonitas y muy importantes de repasar" (Aguilar, 2014).

$\mathrm{Al}$ presentarlo como un hombre comprometido con su profesión, con su tema y su obra, el relato de vida que presentan los directores es el del viaje de redención. Un hombre que sin darse cuenta desciende a los infiernos y debe redescubrir la esperanza. Así, se vuelve necesaria la inclusión de las imágenes desgarradoras de las que se habla en el análisis del nivel 1. El argumento que plantean los directores se sostiene en la evidencia de la crueldad de la especie humana, dicho a voz de Sebastião y evidenciado como verdadero por sus imágenes. La metáfora del terreno familiar en Minas Gerais, que aún seco y sobreexplotado puede reverdecer a través del cuidado y el regreso a la naturaleza primigenia, presenta una analogía que hace aún más contundente el viaje moral del protagonista.

El acercamiento a la recepción de La sal de la tierra, se hará a través de una revisión de las críticas que se han producido en los principales medios de comunicación para buscar comprender la lectura que los especialistas en análisis fílmico han hecho de la cinta. A.O.
Scott (2014) de The New York Times dice que "La sal de la tierra no deja duda acerca del talento o la decencia del Sr. Salgado, y la oportunidad de pasar tiempo en su compañía es una razón para dar gracias", Andrew Pulver (2014) de The Guardian, llama a Salgado un "sujeto magnético" y lo describe como un "tributo emotivo a un talento sin pares". De manera general, los críticos aplauden la figura de Salgado y la forma en que los directores presentan su relato de vida, asegurando que la película es una "maravillosa obra" como lo dice Verónica Sánchez Marín (2014). Rupert Hawksley (2015) de The Telegraph lo llama "un homenaje efusivo" y Stephanie Zacharek (2015) del Village Voice dice que el documental es un "tributo al mismo tiempo grandioso y modesto en su escala”.

Es en el sentido de la identidad narrativa que los críticos cinematográficos aplauden la cinta y a Salgado. Podemos ver la diferente apreciación que hace Sontag (2003) cuando el trabajo de Salgado no ha sido puesto en trama y narrado con un sentido de fin. Se puede pensar que la cinta transparenta la admiración reconocida por Wenders del trabajo de Salgado y la necesidad de J. Salgado de consolidar el mito de su padre, al que la película describe como ausente en su infancia. Nuevamente ayudados por la lectura de los análisis del filme, se puede interpretar que la intencionalidad de los directores era la de presentar a Sebastião Salgado como un hombre sensible, benevolente, que retrata al hombre en sus peores circunstancias para presentar la evidencia de la necesidad de un cambio, y que, decepcionado de la humanidad, emprende él mismo un cambio en su vida y obra.

\section{Nivel 3. La ética del cine como un medio cultural que expresa creencias morales, valores sociales o ideología}

Finalmente, Sinnerbrink (2016, loc. 431-432) habla acerca del interés de los teóricos del cine por las "implicaciones sociales, culturales y políticas del cine”, refiriéndose a la cinematografía como un "medio sintomático de más amplias perspectivas histórico-culturales o ideológicas". Aquí, se abre la puerta para la transdisciplinariedad en el estudio del cine, desde perspectivas feministas, postcoloniales, transnacionales, psicoanalíticas, entre tantas otras que se han convertido en ópticas para los estudios culturales. Resulta problemática, como lo vimos ya en el nivel 1, la representación de los sujetos de las fotografías de Salgado, pero también tenemos que sumar, que igualmente lo resulta la puesta en cámara de las escenas filmadas originalmente para la película. En 
ellas, particularmente Ribeiro, quien filma las secciones a color de la película de acuerdo al press kit que emitió Sony Pictures Classics (2014), adopta al parecer sin reflexionarlo, la mirada misma de su padre.

Se interpreta que la representación que hace Sebastião Salgado de las tribus originales que retrata en distintas partes del mundo y para diferentes proyectos, desde sus inicios en Otras Américas de 1983 hasta Génesis realizado en 2013, mantiene la postura y estética condescendiente de "el buen salvaje" desde una mirada colonial y descontemporaneizante. El documental sigue al fotógrafo y lo retrata con los mismos ojos en su proceso de capturar imágenes en Papúa Nueva Guinea y la selva del Amazonas. Así La sal de la tierra presenta un contraste ideológicamente cargado entre la representación de las tribus primigenias y el fotógrafo occidental.

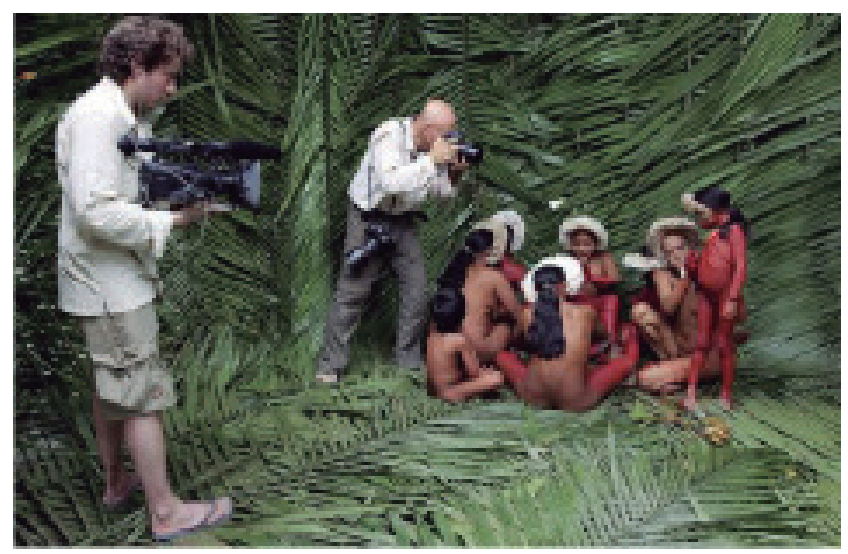

Ter Ellington (2001) en The Myth of the Noble Savage habla de tres mitos. El primero, de que existieron humanos que eran verdaderamente salvajes, no en el sentido original, de "silvestre", sino despiadadamente feroces; el segundo, que dentro de la categoría de los "salvajes" existieron algunos individuos o razas que eran mayormente nobles y vivían en armonía entre ellos y con su entorno; y el tercero, que alguna vez, antes del siglo XIX, existió el concepto de "salvaje noble" o "buen salvaje” como lo entendemos ahora. Así, se propagó la falsa idea del "salvaje" gentil, sabio, que no ha sido corrompido por los vicios de la civilización, y que vive en armonía con su medio. El concepto no solo es condescendiente sino que resulta racista y perpetúa una visión colonial y que ha resultado en una falsa concepción de los pueblos originales fuera de Europa.

También, sigue resultando apropiada la perspectiva de Johannes Fabian (1983) en este argumento. Fabian sostiene un principio, que si bien de alguna manera supera al del "buen salvaje", nos demuestra cómo en las ciencias sociales y en particular en la antropología, se siguen manteniendo enfoques conceptuales donde los académicos e investigadores, al acercarse a los interlocutores en el momento de hacer su trabajo de campo, siempre conceptualizan al "otro" como espacial y temporalmente distanciado. De esta forma se le niega la condición de contemporáneo en el existir de la humanidad. Con el mismo enfoque Sebastião Salgado, retrata a sus sujetos como pertenecientes a un tiempo y espacio que a pesar del evidente dolor de muchos ellos, no comparten

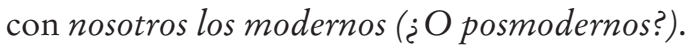

Habrá que anotar aquí que S. Salgado, a pesar de radicarse en Francia desde la década de 1960, es originario de un país postcolonial y que la misma película habla de su postura de izquierda, y aún así, su representación de los otros como "buenos salvajes" implica la existencia de los "malos salvajes", aquellos que los colonizadores eran libres de subyugar. La posición de terratenientes, de evidente ascendencia europea, coloca a la familia de Salgado en esta posición ideológica complicada, desde la cual lo describe su hijo:

Él ve a las personas y no las juzga. Se pone en el mismo nivel que ellos, sin duda porque él también proviene de una pequeña y muy violenta villa en una parte remota de Brasil, separado del mundo. Pienso que la gente que él retrata es sensible a la benevolencia de su punto de vista. (Sony Pictures Classics, 2014)

Estas ideas, contienen frases como "no las juzga" como si lo normal es que hubiera que hacerlo o "se pone en el mismo nivel que ellos" como si ellos por definición estuvieran en un nivel en el que haya que ponerse desde el propio y mejor o más elevado, o asegurando que él mismo estaba "separado del mundo", implicando que ellos, por definición lo están. Y concluye con una frase igualmente difícil: (ellos, los otros) son sensibles a "la benevolencia de su punto de vista" como un dios que viene a traer salvación. (S. Salgado literalmente se compara con Jesucristo en el relato que hace en La sal de la tierra sobre su visita a Ecuador). Pareciera que la admiración y cercanía de los realizadores impide que vean esta representación del otro desde su postura a la vez ingenua y terriblemente discriminatoria.

Ricoeur nos habla del "milagro de la reciprocidad" donde el ser humano se reconoce en el otro:

Tú también eres un ser con iniciativa y elección, capaz de actuar por razones, de jerarquizar fines; $y$, al estimar buenos los objetos de tu búsqueda, eres capaz de estimarte a ti mismo. El otro es, de este modo, el que puede decir yo como yo mismo lo hago y, como tal, tenerse por 
un agente, autor y responsable de sus actos. Si no fuera así, no sería posible ninguna regla de reciprocidad. (2002, p. 243-244)

Al reconocer al otro como sí mismo, se debe eliminar la posible desigualdad para restaurar el balance. Ricoeur habla de que la desigualdad puede

provenir de la debilidad del otro, de su sufrimiento. Es entonces a la compasión a la que corresponde restablecer la reciprocidad, en la medida en que, en la compasión, quien parecía únicamente dar recibe más de lo que ha dado, a través de la gratitud y del reconocimiento. (Ricoeur, 2002, p. 244)

\section{A manera de conclusiones}

Tras un acercamiento al estudio de La sal de la tierra (2014) a través de los tres niveles de análisis que propone Sinnerbrink (2016) es necesario seguir su recomendación de "pensarlos juntos". Es de esta manera que se puede encontrar que hay una vinculación entre la primera denotación del filme, la intencionalidad de los directores, y la operación, quizá inconsciente, dentro de una ideología paradigmática del protagonista y realizadores del documental. La concepción colonial/postcolonial permea las imágenes presentadas por los directores, quienes en los segmentos preparados especialmente para la película repiten el mismo paradigma, resultando ambos en imágenes que resultan éticamente frágiles para los espectadores. Sin embargo, al estudiar la intencionalidad de los directores, es posible darse cuenta que no reparan en ese análisis y construyen un argumento de relato de vida que permite a los críticos de cine interpretarlo como el de un héroe. Este relato, constituye la identidad narrativa que $L a$ sal de la tierra presenta sobre Sebastião Salgado.
Es justo en la identidad narrativa entonces, donde se puede encontrar el relato de una existencia humana. Ricoeur señala: "Es preciso que la vida sea recopilada para que pueda colocarse bajo el enfoque de la verdadera vida. Si mi vida no puede ser aprehendida como una totalidad singular, no podré nunca desear que sea una vida lograda, realizada" (2006, p. 162). Otra dificultad en integrar esa vida buena, añade Ricoeur: el sentido de propósito, de que todas las prácticas y planes de mi vida llevan a alguna parte.

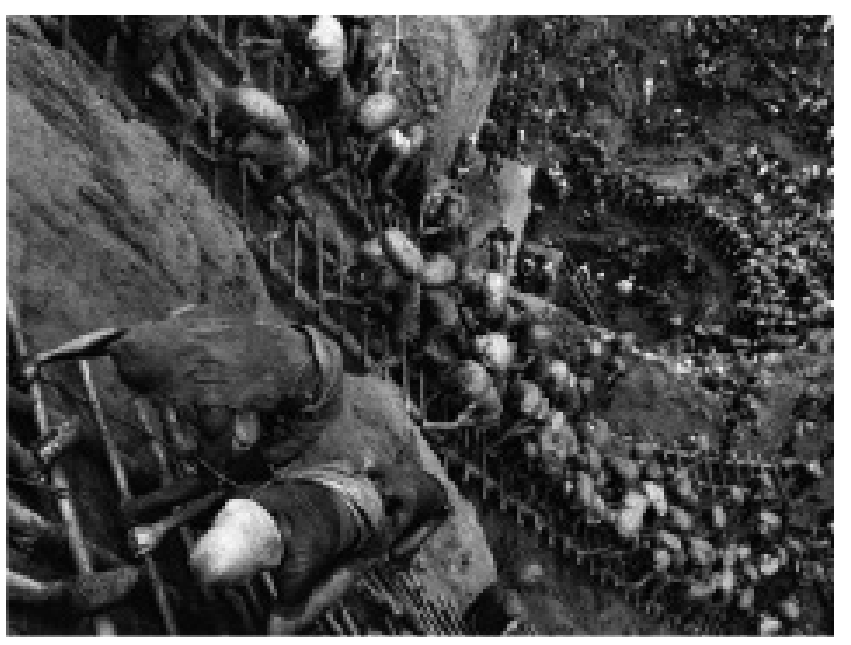

¿Qué pensaría Paul Ricoeur si estuviera sentado en la sala de cine tras haber visto La sal de la tierra? Rupert Hawksley en su crítica de la película, se aventura a decir:

El fotógrafo brasileño Sebastião Salgado ha pasado su carrera documentando el sufrimiento humano. Y sin embargo, este filme silencioso y digno sobre el hombre de 71 años, le dejará retorciéndose de envidia. La de él ha sido, verdaderamente, una vida bien vivida. (2015)

La pregunta al final es si el espectador y el cinéfilo se atreven a asegurar lo mismo.

\section{Referencias}

Aguilar, F. (Director) y Festival Internacional de Cine de Morelia (Productor). (2014, octubre 23). Entrevista: Juliano Ribeiro Salgado [Archivo de video]. Recuperada el 9 de febrero de 2019, de https://youtu.be/SbqVWcukIsU

Badiou, A. (2004). El cine como experimentación filosófica. En G. Yoel (Ed.), Pensar el cine 1: Imagen, ética y filosofía (pp. 23-82). Buenos Aires: Manantial.

Downing, L., y Saxton, L. (2010). Film and ethics: Foreclosed encounters. Londres: Routledge.

Ellingson, T. J. (2001). The myth of the noble savage. Berkeley: University of California Press.

Fabian, J. (1983). Time and the other: How antbropology makes its object. Nueva York: Columbia University Press.

Hawksley, R. (2015, julio 16). The Salt of the Earth review: 'a gushing homage'. Recuperado el 19 de febrero de 2019, de http://www. telegraph.co.uk/film/salt-of-the-earth/review/

imdb.com (s.f.). The Salt of the Earth. Recuperado el 31 de enero de 2019, de http://www.imdb.com/title/tt3674140/ 
Maceiras, M. (2004). Presentación de la edición española. En P. Ricoeur (Autor) \& A. Neira (Trad.), Tiempo y narración I: Configuración del tiempo en el relato histórico. México: Siglo XXI Editores.

Nichols, B. (1997). Axiografía: El espacio ético en el documental. En B. Nichols (Autor) y J. Cerdán y E. Iriarte (Trad.), La representación de la realidad: Cuestiones y conceptos sobre el documental (Primera ed., pp. 115-144). Barcelona, España. Paidós.

Pulver, A. (2014, mayo 20). Cannes 2014: The Salt of the Earth review - photographer Sebastião Salgado is a magnetic subject. Recuperado el 19 de noviembre de 2015, de http://www.theguardian.com/film/2014/may/20/cannes-2014-the-salt-of-the-earthfilm-review-sebastiao-salgado

Ricoeur, P. (2002). Ética y moral. En C. Gómez Sánchez (Ed.), Doce textos fundamentales de la ética del siglo XX. Alianza.

Ricoeur, P. (2006). Sí mismo como otro (Tercera ed.). México, D.F.: Siglo XXI Editores.

Ricoeur, P. (2004). Tiempo y narración I: Configuración del tiempo en el relato histórico (A. Neira, Trad.). México: Siglo XXI Editores.

Ricoeur, P. (2009). Tiempo y narración III: El tiempo narrado (A. Neira, Trad.). México: Siglo XXI Editores.

Rohter, L. (2015, marzo 20). 'The Salt of the Earth’ presents a photographer's life and lens, in focus. Recuperado el 19 de noviembre de 2015, de http://www.nytimes.com/2015/03/22/movies/the-salt-of-the-earth-presents-a-photographers-life-and-lens-in-focus. html

The salt of the earth. (s.f.). Recuperado el 18 de febrero de 2019, de http://www.rottentomatoes.com/m/the_salt_of_the_earth/

Scott, A. O. (2014, diciembre 11). The eyes of a beholder of hardship. Recuperado el 19 de febrero de 2019, de http://www.nytimes. com/2014/12/12/movies/wim-wenders-on-sebastio-salgado-in-the-salt-of-the-earth.html

Simms, K. (2003). Paul Ricoeur. Londres: Routledge.

Sinnerbrink, R. (2016). Cinematic ethics: Exploring ethical experience through film. Nueva York, NY: Routledge. Edición Kindle.

Saito, S. (2015, marzo 27). Wim Wenders \& Juliano Ribeiro Salgado dig deep into Salt of the Earth. Recuperado el 9 de febrero de 2019 de http://moveablefest.com/wim-wenders-juliano-ribeiro-salgado-salt-of-the-earth/

Sánchez Marín, V. (2015, enero 31). Película: La sal de la tierra - minicrítica Ambulante - ENFILME.COM. Recuperado el 19 de febrero de 2019, de http://enfilme.com/en-cartelera/la-sal-de-la-tierra-minicritica-ambulante

Sontag, S. (2003). Regarding the pain of others. Estados Unidos. Farrar, Straus and Giroux. Edición Kindle.

Sony Pictures Classics. (2014). The salt of the earth press kit [Comunicado de prensa]. Recuperado el 31 de enero de 2019, de http:// sonyclassics.com/thesaltoftheearth/thesaltoftheearth_presskit.pdf

Wenders, W., \& Salgado, J. R. (2014). The salt of the earth [Película]. Sony Pictures Classics.

Zacharek, S. (2015, marzo 25). Wenders's Salt of the Earth captures the brilliance of photographer Sebastião Salgado. Recuperado el 20 de febrero de 2019, de http://www.villagevoice.com/film/wenderss-salt-of-the-earth-captures-the-brilliance-of-photographer-sebastiao-salgado-6443954 